\title{
EL MISTERIO ENTRE PLIEGUES Y HENDIDURAS Entrevista con el escultor José Luis Sánchez
}

\author{
Silvia Blanco Agüeira
}

Boletín Académico. Revista de investigación y arquitectura contemporánea

Escuela Técnica Superior de Arquitectura. Universidade da Coruña

elSSN 2173-6723

uww.boletinacademico.com

Número 1 (2011)

Páginas 73-79

Fecha de recepción $\quad 25.10 .2010$

Fecha de aceptación $\quad$ 12.12.2010

https://doi.org/10.17979/bac.2011.1.0.965

\begin{abstract}
Resumen
José Luis Sánchez es uno de los escultores españoles que más se ha prodigado en el campo del arte sacro durante la segunda mitad del siglo XX, siendo numerosas y muy celebradas sus colaboraciones en arquitectura religiosa desde finales de los años cincuenta. El mayor interés de esta entrevista radica en los datos inéditos aportados por el escultor de origen manchego sobre la introducción de las vanguardias artísticas en las iglesias españolas durante un período especialmente interesante para la renovación de la arquitectura sacra en nuestro país.
\end{abstract}

\begin{abstract}
José Luis Sánchez is one of the most important Spanish sculptors in the field of sacred art since the middle of the 20th century: his work in religious architecture from the late fifties has been numerous and celebrated. The interest of this interview lies in the first hand information and untold data provided by the sculptor from La Mancha about the introduction of avant-garde art in the Spanish churches during a particularly interesting period, linked up to a radical change of religious architecture in our country.
\end{abstract}

Palabras clave

Historia del Arte. Escultura. Arquitectura. Espacios sacros. Vanguardias.

\section{Keywords}

History of Art. Sculpture. Architecture. Sacred spaces. Avant-garde. 
José Luis Sánchez Fernández (Almansa, Albacete, 1926) se ha convertido, a lo largo de sus casi sesenta años de trayectoria, en uno de los referentes de la escultura contemporánea española, pues está considerado un precursor de la abstracción en nuestro país. Dentro de la tendencia constructivista de los años sesenta, armó una obra caracterizada por la superposición de pliegues y volúmenes que conformaban juegos espaciales integrados en la arquitectura (Fig. 01). En su empeño por incorporar la escultura a todos los ámbitos de la vida del hombre, introdujo estas creaciones de traza arquitectónica en los espacios sagrados, convirtiéndose en uno de los artistas españoles que más se han prodigado en este campo. Con él conversamos sobre el proceso de renovación del arte sacro que se produjo en España en la segunda mitad del siglo XX, cuando un grupo de arquitectos y artistas decidieron impulsar una reforma en el panorama de la arquitectura religiosa española ${ }^{1}$.

En su opinión, ¿cómo se asimiló la introducción del arte moderno en las iglesias españolas durante ese periodo?

Mal, porque en los seminarios no se enseñaba arte. $\mathrm{Si}$ llegaban a ver arte, se trataba de arte barroco. Pero el arte de los artistas que hacían arte religioso y a la vez pagano, era considerado peligroso en los seminarios. En cambio, las iglesias de colonización - por poner un ejemplo- eran aceptadas como regalo, y cuando he ido a colocar mis imágenes a los pueblos la gente estaba encantada. Por el contrario, en Madrid, la burguesía, que tenía el colmillo más retorcido, se quedaba con la idea de que los artistas éramos una gente muy especial. Así que los artistas íbamos al campo, con ganas de experimentar, de poder hacer cosas, y con la necesidad de hacerlas para poder vivir, porque en aquella época un cuadro $-\mathrm{y}$ no hablemos de una escultura - no tenía acomodo alguno, ni existía una protección oficial de premios y concursos.

Pues eso, nosotros llegábamos al campo y respetábamos lo que podíamos, porque en el campo había una religión de tipo costumbrista con las romerías, las imágenes vestidas, lo ingenuo, y si había una Virgen que se la llevaban de veraneo a la ermita, pues la dejábamos en su sitio, y luego en lo demás íbamos por libre. Y allí trabajaban tanto Pablo Serrano como Manolo Millares o el grupo El Paso. Vegaviana, por ejemplo, que había tenido muchas reticencias, fue premiado por aquella época en Sao Paulo y en Moscú, y entonces las fuerzas vivas, la gente de la administración y los que de verdad decidían pensaban: «Algo bueno tendrá». Pero en el clero no hubo una aceptación. Y en esta época sólo había tres religiosos interesados en el arte sacro, lo que era una cosa bastante grave.

¿Quiénes eran esos impulsores de la renovación del arte sacro?

Imagínese usted que en esa época sólo había tres personas en Espańa que apoyasen decididamente el arte sacro contemporáneo, dentro de un clero que por entonces era muy numeroso: el padre Aguilar, el padre Roig, el padre Plazaola, y podría incluirse aquí al padre Peña, en Madrid. Y nadie más, cuando España por aquella época negreaba... El padre Aguilar era profesor 

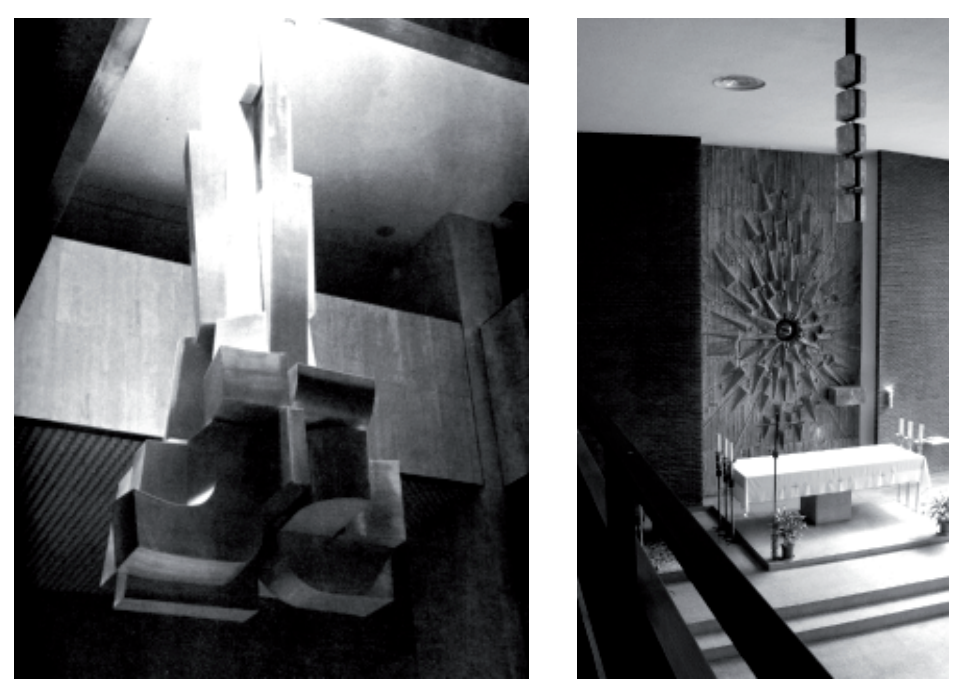

1 Escultura suspendida, antiguo Banco Industrial de León (Madrid, 1975).

2 Retablo de la capilla del Santísimo de la iglesia pa-rroquial de los Sagrados Corazones (Madrid, 1964).

en la Escuela de Bellas Artes de San Fernando de la asignatura Historia sagrada. El padre Roig, profesor de la Escuela de Bellas Artes de Valencia, estaba en contacto con todo el arte moderno francés. En su capilla cercana a Xátiva, creo que ubicada en Luchente, tenía obras de Kandinsky, de Klee, de los grandes artistas que habían colaborado con la Iglesia en Francia, es decir, los pioneros. Aquí llegaba todo con retraso y dentro de una lucha muy especial. Fernández del Amo, que al ser director del Museo de Arte Contemporáneo podía estar en contacto con los artistas, fue el que llevó adelante el tema del Instituto Nacional de Colonización: iglesias que eran aportadas como regalo al pueblo, algo que proporcionaba mucha autoridad a los artistas.

\section{¿Cómo era la relación con el resto del clero?}

Nosotros no teníamos relación con el clero, porque si el contacto era con ellos las cosas no se hacían. Entonces, el prestigio de Rodolfo García-Pablos, Miguel Fisac, José Luis Fernández del Amo, Javier Carvajal y de los otros arquitectos con los que he trabajado, que han sido cientos, era el que imponía la autoridad. La autoridad religiosa, por su parte, la imponía el padre Aguilar, con su hábito y con su talento, pues a él le tenían un respeto, mientras que a nosotros el clero nos consideraba unos seres sospechosos y desviados, de los que no era bueno fiarse.

Precisamente, usted colaboró con Rodolfo Garcia-Pablos en la iglesia de los Sagrados Corazones de Madrid (1961/64). En el archivo profesional del arquitecto se puede leer que el fascinante retablo que usted diseñó para la capilla sacramental representa una versión actualizada del clásico retablo español ¿Podría concretar más esa definición?

Bueno, eso era lo que se pretendía: dar riqueza pero desprovista de argumento. Aquella era una especie de exposición permanente del Santísimo, que estaba en una esfera, y esa esfera estallaba alrededor en cemento (Fig. 02). Porque introducir ese material en aquella época, más o menos enmascarado con baños de plata o de oro, era algo tremendo, algo que la gente rechazaba. Personalmente, no me gustó demasiado el retablo de los Sagrados Corazones; aprecio más el de La Ventilla, en el que yo trabajé desde el principio en una cosa mucho más rica.

Se refiere usted al retablo en hormigón dorado de la iglesia parroquial de San Francisco Javier y San Luis Gonzaga en el barrio madrileño de La Ventilla. ¿Cuál fue su fuente de inspiración?

Antes de La Ventilla, realicé para las Esclavas del Sagrado Corazón un retablo también en cemento dorado y con dosel, que fue premiado en la Bienal de Salzburgo de 1962. Y otra derivación de él fue un retablo para la iglesia de Nuestra Señora de los Remedios, en Sevilla. Más que de la fuente de inspiración de la que habla usted, consistía en tratar el material para hacer una trascripción de la impresión que podía causar un retablo barroco desprovisto de argumento. Yo había estado en México un poco antes de la Exposición Universal de Nueva York. Todos esos retablos coloniales que exis- 


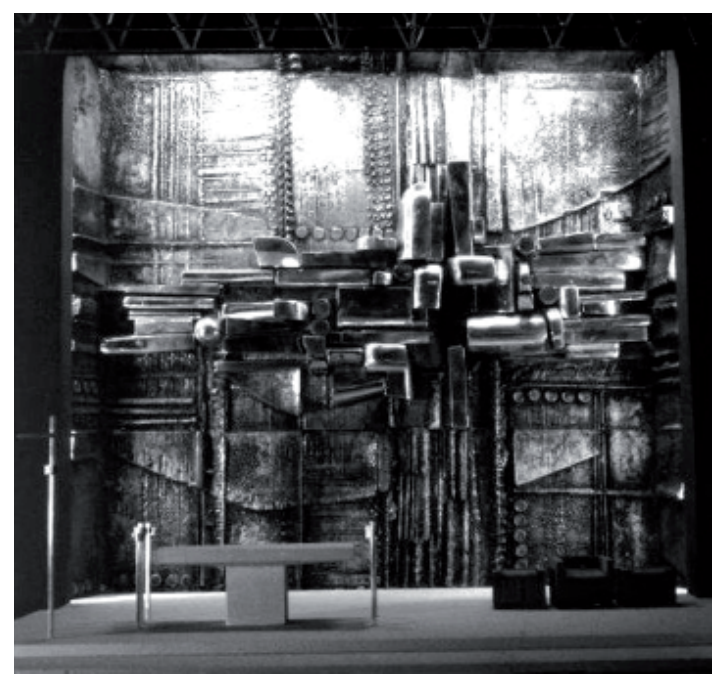

3 Maqueta de retablo de la iglesia parroquial de San Francisco Javier y San Luis Gonzaga (Madrid, 1968)

tían en México, todo ese barroco hispano-azteca me atrajo mucho, y me sirvió de pretexto para lo que yo había propuesto para esa iglesia y que realmente no se construyó.

\section{¿Cuál era esa propuesta inicial?}

En el retablo original todo eran piezas metálicas; había una especie de sugerencia de cruz para presidir un espacio sacro (Fig. 03). Sin embargo, con las quinientas mil pesetas del presupuesto eso no se podía construir, así que se llegó a una cosa más sencilla que fue la que finalmente se realizó. Con esa propuesta definitiva se realizó una maqueta completa de la iglesia, con la cruz de Pablo Serrano en un plano más adelantado, el altar en un lateral, los tubulares del techo y también las vidrieras de Molezún para ver el efecto.

\section{En cualquier caso, el interior de la iglesia de La Ventilla} ha sufrido grandes modificaciones en los últimos años.

Sí, ahora está todo muy cambiado. El crucifijo de Pablo Serrano les horrorizaba tanto que lo quitaron del altar y se lo llevaron a la sacristía. Y ahora han puesto un Cristo que no estaba previsto, porque como ha podido ver, ese retablo era una cruz. Además, el altar yo lo había puesto en un lateral y ellos lo pusieron en el medio. Luego han colocado esa imagen al lado del retablo que no sé lo que representa y que no tiene nada ver con lo otro. ¡No conocen nada! Los manillones de las puertas de entrada son míos (Fig. 04), así como el sagrario y la lámpara del Santísimo. Por otro lado, en el lateral de la nave principal había una pequeña capilla que hizo Vaquero Turcios, las vidrieras eran de Manuel Suárez Molezún, mientras que Pablo Serrano, el que realizó el Cristo que tanto les horrorizaba, fue el autor del san Francisco Javier de la entrada.

Yo he ido a esta iglesia de casualidad, porque yo no vuelvo a las iglesias en las que he trabajado. Además, yo no soy practicante, mi religión es el arte, y cuando me ha tocado hacer arte religioso he hecho arte religioso y punto. Sin embargo, en este caso fuimos Vaquero y yo porque nos llamó el párroco para solucionar una serie de problemas derivados de un incendio, y vimos que aquello era tan distinto de la idea original, tan desastroso todo... El caso es fastidiar. Por esa razón no voy a ver las iglesias en las que he trabajado, porque me llevo unos disgustos horrorosos que me quiero ahorrar, ya que siento que mis obras son como unos hijos que me los han transformado.

Para finalizar, es evidente que la discusión sobre el arte sacro en el templo fue uno de los aspectos más interesantes del debate sobre arquitectura religiosa en los años cincuenta. ¿Cuál fue su manera de enfrentarse a estos encargos para trabajar en el templo?

Yo quise ser arquitecto, pero trabajaba en un banco durante ocho horas y era imposible compaginarlo. En los años cuarenta, la carrera de arquitectura era muy larga, pues incluía los cursos de exactas, de dibujo, de lavado, etc. Pero me quedó esa ansia constructiva que luego he aplicado a mi obra, la cual está muy relacionada con la arquitectura. Yo no he sido un artista de exposiciones, sino que he sido un artista de arquitec- 


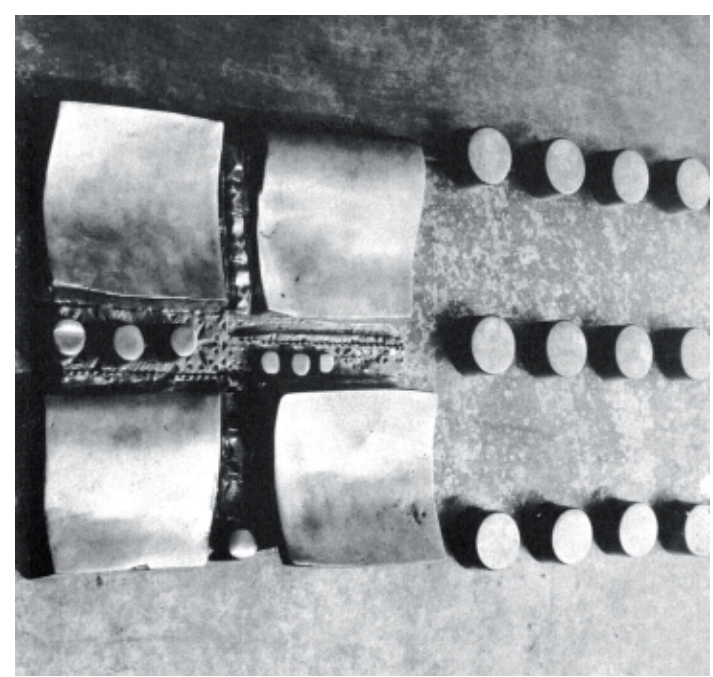

4 Detalle de una puerta de la iglesia parroquial de San Francisco Javier y San Luis Gonzaga (Madrid, 1968).

tos. En una ocasión tuve la paciencia de apuntar el nombre de los arquitectos con los que había trabajado a lo largo de mi carrera aquí, en España, y resultaron ser más de un centenar, lo que constituye una barbaridad. En una clasificación de mayor a menor intensidad, los arquitectos con los que he trabajado son los siguientes: José Luis Fernández del Amo, Javier Carvajal, Rodolfo García-Pablos, Juan Manuel Ruiz de la Prada y Miguel Fisac.

Yo colaboraba principalmente con Fernández del Amo en las iglesias de colonización, que eran trabajos más bien humildes, de bajo presupuesto, mientras que las de García-Pablos eran iglesias bien dotadas económicamente, correspondientes a la época en la que el arzobispo Morcillo quiso hacer una renovación de todas las iglesias de Madrid. El tapón del oscurantismo del primer franquismo y la digestión de la guerra fueron horribles, y todo eso había impedido la llegada de las vanguardias y la llegada de la renovación ¿Y cuál era el mejor camino por el que podría llegar esta renovación? Pues por medio de la Iglesia. En las iglesias, la gente se encontraría una nueva imagen de la realidad, con todo respeto a lo que era el arte tradicional, pero barriendo todo lo que era el arte de Olot y el arte de serie, mientras que ese nuevo arte lo realizábamos los artistas que estábamos metidos en el grupo El Paso —que había comenzado en 1957- y en toda la vanguardia. Se trataba de una labor que requería actuar en los centros de reunión obligatoria de las personas: las iglesias o los colegios, porque a los niños también había que acostumbrarlos a una nueva visión de las cosas, habituarse a una nueva forma de arte que era a su vez una nueva forma de vida. Para poner un ejemplo, en la casa de ejercicios espirituales que realizó Fernández del Amo, las monjas mayores se salían de la orden por culpa de la capilla que habíamos hecho. Sin embargo, me dieron el premio de Salzburgo y al día siguiente ya habían hecho estampitas.

Con todo, mi mejor trabajo ha sido el de la iglesia de Santa Ana, en Moratalaz, con mis esculturas saliendo del hormigón (Fig. 05). He ido a visitarla hace poco con una nieta que se llama Ana para enseñarle lo que había hecho el abuelo. Llego allí y me encuentro con que han puesto alrededor del Cristo unos apliques en forma de lágrimas y unas figuras de papel recortadas con la forma de unos muñecos infantiles que salen en la televisión, y se quedan tan tranquilos. Se queda uno sorprendido y se pregunta: ¿es esto lo que le gusta a la sociedad o esto es lo que ellos quieren imponer? Porque nosotros sí queríamos imponer a la sociedad una forma de arte nuevo, aunque todo eso quedó en el aire... 


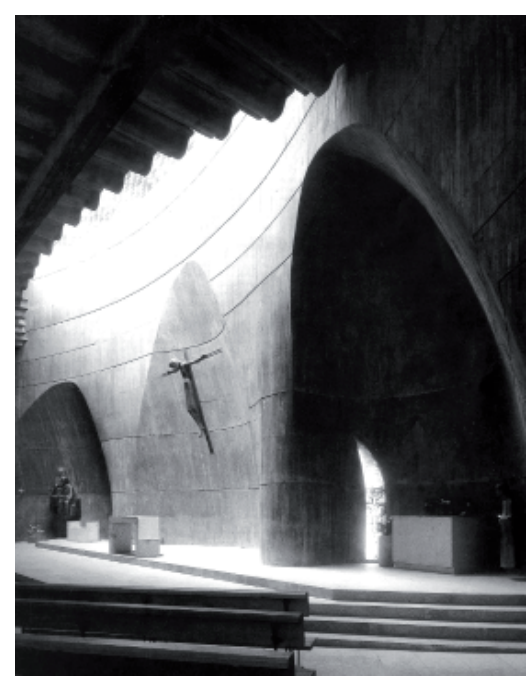

5 Grupo escultórico, iglesia parroquial de Santa Ana (Moratalaz, Madrid, 1967).

En resumen, cuando la integración de las artes resultaba todavía un camino novedoso en nuestro país, José Luis Sánchez ya se encontraba a la cabeza de aquellos que defendían la incorporación de obras de arte vanguardistas a la vida pública para que formaran parte de la cotidianeidad. Es importante observar las consecuencias derivadas de esta decisión, en particular, en el ámbito de los espacios sagrados. Las impresiones recogidas en esta entrevista nos permiten otear el difícil camino que hubo de recorrer su estética renovadora en el espacio de los templos, ahora que cada vez es más difícil encontrar testigos directos de todo aquel proceso. Asimismo, podemos comprobar cómo su iconografía constituyó un ensayo arriesgado en cuanto a la simplificación de las formas y al empleo de nuevos y modestos materiales como el hormigón. Con todo, el rasgo definitorio de su trayectoria parece haber sido el compromiso: un doble respeto hacia la materia de trabajo y hacia el encargo realizado, que demuestra su notable sensibilidad creadora y que incluso clarifica el discreto anonimato de buena parte de su producción artística ${ }^{3}$.

\section{SELECCIÓN DE OBRAS DE JOSÉ LUIS SÁNCHEZ}

Anunciación (1956); pabellón español en la Exposición Universal de Bruselas, 1958.

Bautismo de Cristo (1958); iglesia parroquial de Nuestra Seńora de la Paz, Madrid.

Retablo (1961); casa de ejercicios espirituales para las Esclavas del Sagrado Corazón, Madrid.

Isabel la Católica (1963); pabellón espańol de la Feria Mundial de Nueva York, 1964.

Retablo y puertas de acceso (1964); iglesia parroquial de los Sagrados Corazones, Madrid.

Santa Generación (1967); iglesia de Santa Ana (Moratalaz, Madrid).

Retablo, imágenes y objetos litúrgicos (1967/68); iglesia parroquial de San Francisco Javier y San Luis Gonzaga, Madrid.

Astral flower (1969); Dallas (Texas, Estados Unidos).

Escultura (1975); plaza de Colón, Madrid.

Marea roja (1988); Langreo (Asturias).

La paz aupada (1999); Almansa (Albacete).

La flama (2006); Navalcarnero (Madrid). 


\section{Notas}

${ }^{1}$ Este texto es un extracto de la conversación mantenida el 24 de junio de 2008 con José Luis Sánchez en su residencia madrileńa, con motivo de la realización de la tesis doctoral de la autora.

${ }^{2}$ Cf. Mónica Ruiz Trilleros, Un espacio para la escultura. José Luis Sánchez en el ayuntamiento de Almansa (Albacete: Ayuntamiento de Almansa, 2007), 15. Para más información véase también el libro de la misma autora José Luis Sánchez. Trayectoria de un escultor (Toledo: Junta de Comunidades de Castilla-La Mancha, 2010); Andrés Trapiello García, José Luis Sánchez. El rescate de los signos (Madrid: Rayuela, 1976; Varios autores, José Luis Sánchez: casi treinta años de oficio de escultor (Madrid: Dirección General de Bellas Artes, Archivos y Bibliotecas, 1981). En cuanto a las publicaciones de carácter más general podemos destacar: María Teresa González Vicario, Aproximación a la escultura religiosa contemporánea en Madrid (Madrid: UNED, 1987); José Marín Medina, La escultura española contemporánea (1800-1978). Historia y evaluación crítica (Madrid: Edarcón, 1978).

${ }^{3}$ Con motivo de la presentación del catálogo correspondiente a la exposición retrospectiva organizada en Ciudad Real en el ańo 2010, José Luis Sánchez concedía una entrevista al periodista del diario ABC Sergio Daniel Bote Seco, en la que manifestaba el gran desconocimiento que el público posee de su obra: «Y no me quejo. He dejado una marca modesta" ("Hay quien conoce mis obras, pero no a mí", ABC 14/07/2010, 59).

\section{Procedencia de las ilustraciones}

Fig. 01. Varios autores, José Luis Sánchez: casi treinta años de oficio de escultor (Madrid: Dirección General de Bellas Artes, Archivos y Bibliotecas, 1981).

Fig. 02. Archivo Silvia Blanco Agüeira.

Fig. 03. Archivo profesional de José Luis Sánchez Fernández.

Fig. 04. Archivo profesional de Rodolfo García-Pablos y González-Quijano.

Fig. 05. Revista AV Monografías 101 (2003).

\section{Sobre la autora}

Silvia Blanco Agüeira. Doctora en Arquitectura por la Universidade da Coruńa (2009) con la tesis doctoral Rodolfo García-Pablos: la construcción del espacio sagrado. Profesora de Proyectos en el Centro de Estudios Superiores de Galicia (CESUGA- University College Dublin), ha participado en numerosos congresos nacionales e internacionales de temática ligada a la arquitectura religiosa contemporánea y, en general, a la historia de la arquitectura. Ha sido técnica especialista en programas de rehabilitación de la Xunta de Galicia, y ha colaborado en varios estudios de arquitectura gallegos. En cuanto a las principales publicaciones, se pueden destacar las siguientes: "Los viajes de Rodolfo García-Pablos: inspiración para una nueva arquitectura”, en Varios autores, Viajes en la transición de la arquitectura española hacia la modernidad (Pamplona: T6/Universidad de Navarra, 2010); "El hormigón armado en el espacio sacro contemporáneo", en Varios autores, CIAB 4 (Valencia: General de Ediciones de Arquitectura, 2010); y "Rodolfo García-Pablos; el proyecto del espacio sagrado", en Esteban Fernández Cobián (ed.), Arquitecturas de lo sagrado. Memoria y proyecto (A Coruña: Netbiblo, 2009).

silviablanco@coag.es 